p-ISSN : 2541-2345, e-ISSN : 2580-8842

\title{
BENTUK PEMERINTAHAN PERSPEKTIF OMNIBUS LAW
}

\author{
Tomy Michael \\ Fakultas Hukum Universitas 17 Agustus 1945 Surabaya \\ tomy@untag-sby.ac.id
}

\begin{abstract}
Abstrak
Penelitian ini bertujuan mengetahui bentuk pemerintahan demokrasi secara tepat ketika omnibus law diterapkan. Metode penelitian yang digunakan dalam penelitian ini menggunakan metode analitis hukum. Temuan penelitian adalah bentuk pemerintahan perspektif omnibus law merupakan demokrasi gabungan Plato dan Polybius karena tujuan akhir adalah kesejahteraan masyarakat yang dikombinasikan dengan kekausaan negara secara secara utuh. Kekuasaan negara secara utuh bukan semena-mena melainkan tetap dibatasi kehdenak dari masyarakat itu sendiri. Adanya bentuk gabungan bentuk pemerintahan demokrasi akan meniadakan makna demokrasi ekonomi seperti dalam Pasal 33 Undang-Undang Dasar Negara Republik Indonesia Tahun 1945. Demokrasi ekonomi tersebut bukanlah bentuk pemerintahan melainkan sebutan untuk mendefinisikan makna negara dari Pasal 33 Undang-Undang Dasar Negara Republik Indonesia Tahun 1945. Dampak dari temuan ini akan membatasi omnibus law yang pada awalnya bagian dari kekuasaan negara secara mutlak. Adanya penggabungan bentuk demokrasi gabungan Plato dan Polybius merupakan penegasan akan demokrasi yang dianut oleh Indonesia. Penggabungan harus segera dijadikan dasar dalam segala hal karena adanya omnibus law juga bertentangan dengan demokrasi menurut Plato yang awalnya mensejahterahkan rakyat dengan menerima masukan dari segala masyarakat untuk langgengnya negara. Tetapi negara juga tidak dapat mengetahui kapan omnibus law harus dilakukan negara, karena sifatnya yang tiba-tiba maka pelegalan bentuk pemerintahan Plato dan Polybius segera dilakukan. Penerapan omnibus law tetap harus melalui pengawasan Dewan Perwakilan Rakyat agar tercipta check and balances serta partisipasi masyarakat sesuai Undang-Undang Republik Indonesia Nomor 15 Tahun 2019 tentang Perubahan Atas Undang-Undang Nomor 12 Tahun 2011 Tentang Pembentukan Peraturan Perundang-Undangan.
\end{abstract}

Kata kunci: pemerintahan; omnibus law; demokrasi 
p-ISSN : 2541-2345, e-ISSN : 2580-8842

\title{
FORM OF OMNIBUS LAW PERSPECTIVE GOVERNMENT
}

\author{
Tomy Michael \\ Faculty of Law, Universitas 17 Agustus 1945 Surabaya \\ tomy@untag-sby.ac.id
}

\begin{abstract}
This study aims to determine the exact form of democratic government when the omnibus law is applied. The research method used in this study uses the legal analytical method. The research findings are a form of government from the perspective of the omnibus law which is a combined democracy of Plato and Polybius because the ultimate goal is the welfare of the people combined with the state's integrity as a whole. Whole state power is not arbitrary but is still restricted from the existence of the community itself. The existence of a combined form of democratic form of government will negate the meaning of economic democracy as in Article 33 of the 1945 Constitution of the Republic of Indonesia. Economic democracy is not a form of government but a term to define the meaning of the state from Article 33 of the 1945 Constitution of the Republic of Indonesia. The impact of this finding will limit the omnibus law which was originally part of the state power absolutely. The existence of a merging form of democracy combined Plato and Polybius is an affirmation of democracy adopted by Indonesia. Merger must immediately be used as a basis in all matters because the existence of omnibus law is also contrary to democracy according to Plato, who initially prospered the people by receiving input from all communities for the continuity of the state. But the state also cannot know when the omnibus law must be carried out by the state, because of its sudden nature, the legalization of the form of government of Plato and Polybius was immediately carried out. The application of the omnibus law must still go through the supervision of the House of Representatives in order to create checks and balances as well as public participation in accordance with the Law of the Republic of Indonesia Number 15 of 2019 concerning Amendments to Law Number 12 of 2011 concerning the Formation of Legislation.
\end{abstract}

Keywords: government; omnibus law; democracy 
p-ISSN : 2541-2345, e-ISSN : 2580-8842

\section{PENDAhULUAN}

\section{A. Latar Belakang}

Omnibus law menguntungkan dari segi biaya dan waktu, ${ }^{1}$ tetapi terdapat berbagai penolakan. Penolakan terjadi setelah Presiden Joko Widodo melakukan pidato dalam Sidang Paripurna Majelis Permusyawaratan Rakyat Republik Indonesia Dalam Rangka Pelantikan Presiden Dan Wakil Presiden Terpilih 2019-2024 terdapat berbagai argumen hukum dalam menyikapi isi pidato yang disampaikan Presiden Joko Widodo. Mengacu pada Pasal 1 ayat (3) Undang-Undang Dasar Negara Republik Indonesia Tahun 1945 bahwa acuan kita adalah negara hukum. Di dalam konsep demikian, segala sesuatuya berdasarkan hukum.

Argumen yang muncul ketika presiden menyampaikan bahwa adanya omnibus law sebagai wujud mengesampingkan beberapa undang-undang yang muncul ${ }^{2}$ maka

${ }^{1}$ Glen S. Krutz, Tactical Manuevering on Omnibus Bills in Congress, American Journal of Political Science, Vol 45, No 1 (January 2001); Denis Kirchhoff and Leonard J.S. Tsuji, Reading between the lines of the 'Responsible Resource Development' rhetoric: the use of omnibus bills to 'streamline' Canadian environmental legislation, Impact Assessment and Project Appraisal, 2014 Vol. 32, No. 2; Louis Massicotte, Omnibus Bills in Theory and Practice, Canadian Parliamentary Review, 2013.

${ }^{2}$ Bapak, Ibu, Saudara-Saudara sebangsa \& setanah air, Mimpi kita, cita-cita kita di tahun 2045 pada satu abad Indonesia merdeka mestinya, Insya Allah, Indonesia telah keluar dari jebakan pendapatan kelas menengah. Indonesia telah menjadi negara maju dengan pendapatan menurut hitunghitungan Rp320 juta per kapita per tahun atau Rp 27 juta per kapita per bulan. Itulah target kita. Target kita bersama. Mimpi kita di tahun 2045, Produk Domestik Bruto Indonesia mencapai US\$ 7 triliun. Indonesia sudah masuk 5 besar ekonomi dunia dengan kemiskinan mendekati nol persen. Kita harus menuju ke sana. Kita sudah hitung, sudah kalkulasi, target tersebut sangat masuk akal dan sangat memungkinkan untuk kita capai. Namun, semua itu tidak datang otomatis, tidak datang dengan mudah. Harus disertai kerja keras, dan kita harus kerja cepat, harus disertai kerja-kerja bangsa kita yang produktif. Dalam dunia yang penuh risiko, yang sangat dinamis, dan yang kompetitif, kita harus terus mengembangkan cara-cara baru, nilai-nilai baru. Jangan sampai kita terjebak dalam rutinitas yang monoton. Harusnya inovasi bukan hanya pengetahuan. Inovasi adalah budaya. Cerita sedikit, tahun pertama saya di istana, saat mengundang masyarakat untuk halalbihalal, protokol meminta saya untuk berdiri di titik itu, saya ikut. Tahun kedua, halalbihalal lagi, protokol meminta saya berdiri di titik yang sama, di titik itu lagi. Langsung saya bilang ke Mensesneg, "Pak, ayo kita pindah lokasi. Kalau kita tidak pindah, akan jadi kebiasaan. Itu akan dianggap sebagai aturan dan bahkan nantinya akan dijadikan seperti undang-undang." Ini yang namanya monoton dan rutinitas. Sekali lagi, mendobrak rutinitas 
adalah satu hal. Meningkatkan produktivitas adalah hal lain yang menjadi prioritas. Jangan lagi kerja kita berorientasi proses, tapi harus berorientasi pada hasil-hasil yang nyata. Saya sering ingatkan ke para menteri, tugas kita bukan hanya membuat dan melaksanakan kebijakan, tetapi tugas kita adalah membuat masyarakat menikmati pelayanan, menikmati hasil pembangunan. Seringkali birokrasi melaporkan bahwa program sudah dijalankan, anggaran telah dibelanjakan, dan laporan akuntabilitas telah selesai. Kalau ditanya, jawabnya "Program sudah terlaksana Pak." Tetapi, setelah dicek di lapangan, setelah saya tanya ke rakyat, ternyata masyarakat belum menerima manfaat. Ternyata rakyat belum merasakan hasilnya. Sekali lagi, yang utama itu bukan prosesnya, yang utama itu hasilnya. Cara mengeceknya itu mudah. Lihat saja ketika kita mengirim pesan melalui SMS atau WA. Ada sent, artinya telah terkirim. Ada delivered, artinya telah diterima. Tugas kita itu menjamin delivered, bukan hanya menjamin sent. Saya tidak mau birokrasi pekerjaannya hanya sending-sending saja. Saya minta dan akan saya paksa bahwa tugas birokrasi adalah making delivered. Tugas birokrasi itu menjamin agar manfaat program dirasakan oleh masyarakat. Para hadirin dan seluruh rakyat Indonesia yang saya banggakan, Potensi kita untuk keluar dari jebakan negara berpenghasilan menengah sangat besar. Saat ini, kita sedang berada di puncak bonus demografi, di mana penduduk usia produktif kita jauh lebih tinggi dibandingkan usia tidak produktif. Ini adalah tantangan besar dan sekaligus juga sebuah kesempatan besar. Ini menjadi masalah besar jika kita tidak mampu menyediakan kesempatan kerja. Tapi akan menjadi kesempatan besar jika kita mampu membangun SDM yang unggul. Dengan didukung oleh ekosistem politik yang kondusif dan dengan ekosistem ekonomi yang kondusif. Oleh karena itu, 5 tahun ke depan yang ingin kita kerjakan: Pertama, pembangunan SDM akan menjadi prioritas utama kita, membangun SDM yang pekerja keras, yang dinamis. Membangun SDM yang terampil, menguasai ilmu pengetahuan dan teknologi. Mengundang talenta-talenta global bekerja sama dengan kita. Itupun tidak bisa diraih dengan cara-cara lama, cara-cara baru harus dikembangkan. Kita perlu endowment fund yang besar untuk manajemen SDM kita. Kerja sama dengan industri juga penting dioptimalkan. Dan juga penggunaan teknologi yang mempermudah jangkauan ke seluruh pelosok negeri.

Kedua, pembangunan infrastruktur akan kita lanjutkan. Infrastruktur yang menghubungkan kawasan produksi dengan kawasan distribusi, yang mempermudah akses ke kawasan wisata, yang mendongkrak lapangan kerja baru, yang mengakselerasi nilai tambah perekonomian rakyat. Ketiga, segala bentuk kendala regulasi harus kita sederhanakan, harus kita potong, harus kita pangkas. Pemerintah akan mengajak DPR untuk menerbitkan 2 undang-undang besar. Pertama, UU Cipta Lapangan Kerja. Kedua, UU Pemberdayaan UMKM. Masing-masing UU tersebut akan menjadi Omnibus law, yaitu satu UU yang sekaligus merevisi beberapa UU, bahkan puluhan UU. Puluhan UU yang menghambat penciptaan lapangan kerja langsung direvisi sekaligus. Puluhan UU yang menghambat pengembangan UMKM juga akan langsung direvisi. Keempat, penyederhanaan birokrasi harus terus kita lakukan besar-besaran. Investasi untuk penciptaan lapangan kerja harus diprioritaskan. Prosedur yang panjang harus dipotong. Birokrasi yang panjang harus kita pangkas. Eselonisasi harus disederhanakan. Eselon I, eselon II, eselon III, eselon IV, apa tidak kebanyakan? Saya minta untuk disederhanakan menjadi 2 level saja, diganti dengan jabatan fungsional yang menghargai keahlian, menghargai kompetensi. Saya juga minta kepada 
pemahaman akan negara hukum menjadi sirna. Konsep negara hukum di Indonesia sudah berubah setelah dilakukan amandemen Undang-Undang Dasar Tahun 1945. Setelah amandemen, konsep negara hukum di Indonesia bukan lagi rechtsstaat atau rule of law, melainkan Negara Hukum Indonesia. Maksud penegasan ini memiliki makna sangat penting, terutama jika dikaitkan dengan sistem hukum yang sudah ada di dunia. Konsep negara hukum rechtsstaat dan rule of law sangat berpengaruh bagi negara hukum Indonesia. ${ }^{3}$

Hal ini selaras dengan pendapat Robert L. Nightingale bahwa omnibus law bagian dari identifikasi area yang tidak dapat dilakukan identifikasi karena area yang dimaksud harus memiliki bentukan baru. Bentukan baru haruslah dilakukan oleh

para menteri, para pejabat dan birokrat, agar serius menjamin tercapainya tujuan program pembangunan. Bagi yang tidak serius, saya tidak akan memberi ampun. Saya pastikan, pasti saya copot. Pada akhirnya, yang kelima adalah transformasi ekonomi. Kita harus bertransformasi dari ketergantungan pada sumber daya alam menjadi daya saing manufaktur dan jasa modern yang mempunyai nilai tambah tinggi bagi kemakmuran bangsa demi keadilan sosial bagi seluruh rakyat Indonesia. Para hadirin dan seluruh rakyat Indonesia yang saya muliakan, pada kesempatan yang bersejarah ini, perkenankan saya, atas nama pribadi, atas nama Wakil Presiden K.H. Ma'ruf Amin, dan atas nama seluruh rakyat Indonesia, menyampaikan terima kasih dan penghargaan setinggi-tingginya kepada Bapak Muhammad Jusuf Kalla yang telah bahu-membahu menjalankan pemerintahan selama 5 tahun terakhir. Ucapan terima kasih juga saya sampaikan kepada seluruh lembaga-lembaga negara, kepada jajaran aparat pemerintah, TNI dan Polri, serta seluruh komponen bangsa yang turut mengawal pemerintahan selama 5 tahun ini sehingga dapat berjalan dengan baik. Mengakhiri pidato ini, saya mengajak saudara-saudara sebangsa dan setanah air untuk bersama-sama berkomitmen: "Pura babbara' sompekku...Pura tangkisi' golikku..." "Layarku sudah terkembang...Kemudiku sudah terpasang..." Kita bersama Menuju Indonesia maju!!!.

3 Arif Hidayat dan Zaenal Arifin, Politik Hukum Legislasi Sebagai Socio-Equilibrium Di Indonesia, Jurnal Ius Constituendum | Volume 4 Nomor 2 Oktober 2019 Magister Hukum Program Pascasarjana Universitas Semarang. 
negara dengan melingkupi banyak hal. ${ }^{4}$ Didalam konteks demikian, negara hukum bisa ditafsirkan negara yang cara mempertahankannya tidak sesuai hukum tetapi lebih tertuju pada bagian akhir karena omnibus law bagian dari penyelesaian seluruh aspek masalah.

Di dalam tulisan ini, fokus penulis bukan mengarah pada penting atau tidaknya omnibus law melainkan menerka bentuk pemerintahan apabila omnibus law diterapkan di Indonesia. Pendapat menarik oleh Robert L. Nightingale bawa pembuatan undang-undang omnibus tergantung pada penggunaan satu kendaraan hukum, sebuah undang-undang yang diusulkan, diperdebatkan, diamandemen, dan disahkan - untuk meloloskan sejumlah ketentuan. Dikatakan juga bahwa omnibus law sebagai "[1] peraturan perundang-undangan yang membahas banyak hal, masalah, dan program yang tidak harus terkait, dan karenanya biasanya sangat kompleks dan panjang."5 Pendapat Robert L. Nightingale memiliki perbedaan konsep bahwa omnibus law biasanya "berisi satu RUU berbagai hal berbeda, biasanya dirancang sedemikian rupa untuk memaksa eksekutif baik untuk menerima semua ketentuan kecil yang tidak terkait atau untuk memveto ketentuan utama. " Menurut definisi, omnibus law menghasilkan kompromi. ${ }^{6}$ Perbandingan kedua ketika omnibus law sebagai penegakan hukum saja maka juga terait dengan demokrasi. Prinsip demokrasi mengandung arti dijunjung tingginya hak setiap orang untuk berpendapat, untuk memiliki ideologi tertentu, dan untuk memiliki identitas tertentu serta menghargai setiap pendapat yang keluar dari pikiran setiap orang. Konsep demokrasi menjadi sebuah kata kunci tersendiri dalam bidang ilmu politik. Prinsip semacam trias politica ini menjadi sangat penting untuk diperhitungkan ketika fakta-fakta sejarah mencatat kekuasaan pemerintah (eksekutif) yang begitu besar ternyata tidak mampu untuk

4 Robert L. Nightingale, How To Trim a Christmas Tree: Beyond Severability and Inseverabilityfor Omnibus Statutes, Yale Law Journal: Volume 125, Number 6 - April 2016.

${ }^{5}$ Robert L. Nightingale, How To Trim a Christmas Tree: Beyond Severability and Inseverability for Omnibus Statutes, 125 Yale L.J. (2016).

${ }^{6}$ McCabe, Margaret Sova (2018) "Cooperation or Compromise? Understanding the Farm Billas Omnibus Legislation," Journal of Food Law \& Policy: Vol. 14 : No. 1 , Article 5. 
membentuk masyarakat yang adil dan beradab, bahkan kekuasaan absolut pemerintah seringkali menimbulkan pelanggaran terhadap hak-hak asasi manusia. ${ }^{7}$

Penelitian ini membahas bentuk pemerintahan perspektif omnibus law. Dalam kajian hukum di Amerika, omnibus law dikenal dengan omnibus bill dan merupakan kebebasan dalam membentuk suatu peraturan dari legislatif. Para anggota bebas menentukan cara untuk menentukan suatu tujuan dan cara apapun bisa dilakukan agar cara tersebut tercapai. Namun permasalahannya apakah cara tersebut ilegal atau legal? Oleh karena itu pembatasan adalah hal yang wajib karena kebebasan dalam menentukan hukum akan memunculkan peraturan yang tidak sesuai dengan keadilan hukum. Pengadian persemakmuran Pennsylvania memberikan argumen menarik yaitu "Bills, popularly called omnibus bills, became a crying evil, not only from the confusion and distraction of the legislative mind by the jumbling together of incongruous subjects, but still more by the facility they afforded to corrupt combinations of minorities with different interests to force the passage of bills with provisions which could never succeed if they stood on their separate merits. So common was this practice that it got a popular name, universally understood, as logrolling. A still more objectionable practice grew up, of putting what is known as a rider (that is, a new and unrelated enactment or provision) on the appropriation bills, and thus coercing the executive to approve obnoxious legislation, or bring the wheels

\footnotetext{
${ }^{7}$ Muten Nuna dan Roy Marthen Moonti, Kebebasan Hak Sosial-Politik Dan Partisipasi Warga Negara Dalam Sistem Demokrasi Di Indonesia, Jurnal Ius Constituendum |Volume 4 Nomor 2 Oktober 2019 Magister Hukum Program Pascasarjana Universitas Semarang.
} 
p-ISSN : 2541-2345, e-ISSN : 2580-8842

of the government to a stop for want of funds." ${ }^{\prime}$. Perhatikan bunyi Pasal 33 UndangUndang Dasar Negara Republik Indonesia Tahun 1945 dimana kita menganut demokrasi ekonomi. Tiadanya kejelasan definisi bentuk pemerintahan yang lain selain demokrasi ekonomi secara tersurat maka bentuk pemerintahan lainnya tidak dilarang namun tidak memiliki legalitas. ${ }^{9}$

8 Louis Massicotte, Omnibus Bills in Theory and Practice, Canadian Parliamentary Review/Spring 2013.

Bandingkan juga "An omnibus bill is a bill that addresses a subject comprehensively. The constitution's single-subject rule ("No law shall embrace more than one subject which shall be expressed in its title") and supporting legislative rules are designed to curb the creation of sprawling bills with provisions on disparate subjects. But a bill dealing comprehensively with one subject-an omnibus bill-is permitted.", lebih lanjut dalam Tom Todd, The Research Department of the Minnesota House of Representatives, Minnesota, 2018, hlm. 25.

Pengembangan harmonisasi hukum sudah muncul di Jerman tahun 1902. Rudolf Stammler mengemukakan suatu konsep fungsi hukum adalah harmonisasi berbagai maksud, tujuan dan kepentingan antara individu dengan individu dan antara individu dengan masyarakat. Kemudian dalam praktik hukum di Roma tahun 1926, International Institute for the Unification of Private Law (UNIDROIT) Badan Internasional yang didirikan menurut perjanjian multilateral yang difasilitasi oleh Persatuan Bangsa Bangsa (United Nations) telah menciptakan cara untuk mengharmonisasikan dan mengkoordinasikan ketentuan-ketentuan Hukum Perdata dari negara-negara anggotanya.

Pada Tahun 1951 di Paris terbentuk Verdrag van Parijs tot Oprichting van Europese Gemeenschap voor Kolen en Staal (masyarakat Batubara dan Baja Eropa) melalui Perjanjian Paris 1951. Kemudian diikuti dengan Perjanjian Roma 1957 terbentuk European Gemeenschap van Atoomenergie (Masyarakat Energi dan Atom Eropa) dan European Economic Community (Masyarakat Ekonomi Eropa). Secara bersama merupakan kesatuan European Community dalam usaha integrasi ekonomi yang diwujudkan terutama melalui harmonisasi hukum di antara negara-negara anggota. Harmonisasi hukum juga berkembang dalam ilmu hukum di Belanda sejak tahun 1970.Pemerintah Belanda membentuk Inter Departmental Commision for Harmonization of Legislation dan membentuk Ministry of Justice a Staff Bureau for Harmonization. Sehubungan dengan tujuan harmonisasi hukum tersebut, dikeluarkan petunjuk kepada semua lembaga pemerintahan di Belanda untuk melakukan harmonization of legislation, lebih lanjut dalam Firman Freaddy Busroh, Konseptualisasi Omnibus Law Dalam Menyelesaikan Permasalahan Regulasi Pertanahan, ARENA HUKUM Universitas Brawijaya, Volume 10, Nomor 2, Agustus 2017, Halaman 227-250.

${ }^{9}$ Bandingkan dengan pendapat bahwa One of the biggest benefits of federalism - and one of the biggest criticisms of a federal omnibus privacy law - is that it allows for state experimentation. Critics argue that "[t]he preemptive scope of an omnibus federal privacy law [would be] likely to block new approaches to information privacy." Additionally, states are more often the "first to act in response to 
new problems or issues, of which many arise in a time of rapid technological and cultural change." While innovation is important, and it is true that innovation and experimentation occur more effectively at the state level, that very experimentation has, in effect, undermined security compliance, lebih lanjut dalam Carol Li, A Repeated Call For Omnibus Federal Cybersecurity Law, Notre Dame Law Review, Vol. 94:5.

But several contributors to this Symposium powerfully challenge this notion of "equality." States, they argue, simply cannot be treated like private litigants. As Ann Woolhandler and Michael Collins point out, states-in their role as operators of public universities, police departments, prisons, healthcare networks, and highways and other infrastructure programs-may be injured by an almost infinite number of federal actions, lebih lanjut dalam Tara Leigh Grove, Symposium Foreword: Some Puzzles Of State Standing, Notre Dame Law Review, Vol. 94:5.

Perhatikan Pasal 33 ayat (4) Undang-Undang Dasar Negara Republik Indonesia Tahun 1945 bahwa demokrasi ekonomi adalah pilihan Indonesia yang berasaskan kebersamaan, efisiensi berkeadilan, berkelanjutan, berwawasan lingkungan, kemandirian, menjaga keseimbangan kemajuan dan kesatuan ekonommi nasional. Apabila dibandingkan dengan demokrasi yang awal bahwa demokrasi tidak merupakan bagian dari ekonomi melainkan tindakan untuk menentukan pemimpin. Demokrasi sebagai cerminan demokrasi deliberatif yang bersifat sangat adil dikarenakan adanya pemberian penghargaan atas setiap suara masyarakat. Penghargaan disini adalah mempertimbangkan akan hal yang diutarakan dan tetap menjadi bagian dari pengambilan keputusan besar. Kemudian melihat Pasal 1 ayat (2) Undang-Undang Dasar Negara Republik Indonesia Tahun 1945 bahwa kedaulatan berada di tangan rakyat dan dilaksanakan menurut Undang-Undang Dasar. Pemahaman demikian apabila mengacu pada pemikiran Plato bahwa kedaulatan demikian menunjukkan bahwa rakyat yang berkuasa dan tidak adanya kesempatan bagi pemimpin bijaksana untuk menunjukkan keugahariannya dalam memimpin. Bandingkan juga bunyi Pasal 1 ayat (1) Undang-Undang Dasar Negara Republik Indonesia Tahun 1945 bahwa negara kesatuan yang berbentuk republik. Mengacu pada pemikiran Immanuel Kant dalam bukunya berjudul Menuju Perdamaian Abadi Sebuah Konsep Filosofi bahwa republik identik dengan maksud negara dalam menciptakan perdamaian. Immanuel Kant menawarkan suatu negara tidak berpatokan pada bentuk pemerintahan tetapi mengarah pada sifat negara dalam menghadapi musuh. Kedamaian haruslah menjadi perhatian utama suatu negara dimana salah satunya harus berbentuk republik disamping syarat lainnya berupa penghapusan tentara, tidak adanya perjanjian dengan negara lain yang tidak menguntungkan atau lepas tangan akan urusan teritori negara lain, lebih lanjut dalam 
Penelitian ini membandingkan dengan 2 (dua) jurnal ilmiah yaitu penelitian yang terkait solusi hiperregulasi menuju sinkronisasi dan harmonisasi peraturan perundang undangan di Indonesia. Hasil penelitian menujukkan bahwa penerapan konsep omnibus law sebagai solusi hiperregulasi regulasi di Indonesia. Hiperegulasi di Indonesia terjadi pada setiap tingkatan peraturan perundang undangan. Potensi tumpang tindih peraturan perundang undagan diantarannya terdapat 7621 peraturan menteri, 765 peraturan presiden, 452 peraturan pemerintah dan sekitar 30.000 peratruan daerah. Hiperregulasi tersebut memberikan beban dalam melakukan sinkronisasi dan harmonisasi peraturan perundang undangan di Indonesia. Sinkronisasi dan Harmonisasi dilakukan dalam kerangka empat pilar sebagai dasar negara Rebublik Indonesia. Dengan demikian, perlu dilakukan diterapkannya kajian penerapan omnibu law sebagai solusi atas hiperregulasi perundang undangan di

Kurt Taylor Gaubatz, Kant, Democracy And History, Journal of Democracy Volume 7 Number 4 October 1996.

Penelitian ini memasukkan pemikiran Immanuel Kant untuk menekankan bahwa demokrasi sebetulnya bukanlah bagian secara murni di Indonesia melainkan adanya unsur bentuk-bentuk pemerintahan lain. Demokrasi memberikan pemahaman, bahwa dari sebuah kekuasaan dari rakyat. Dengan pemahaman seperti itu, rakyat akan melahirkan sebuah aturan yang menguntungkan dan melindungi hak-haknya. Agar itu bisa terlaksana, diperlukan sebuah peraturan bersama yang mendukung dan menjadi dasar pijakan dalam kehidupan bernegara untuk menjamin dan melindungi hak-hak rakyat, lebih lanjut dalam Muten Nuna dan Roy Marthen Moonti, Kebebasan Hak Sosial Politik Dan Pasrtisipasi Warga Negara Dalam Sistem Demokrasi Di Indonesia, Jurnal Ius Constituendum | Volume 4 Nomor 2 Oktober 2019, Program Pascasarjana Universitas Semarang.

SL Witman dan JJ.Wuest mengemukakan bahwa bentuk pemerintahan berdasarkan pembagian kekuasaan namun harus ada pembatasan antara eksekutif dan legislatif, lebih lanjut dalam Muliadi Anangkota, Klasifikasi Sistem Pemerintahan Perspektif Pemerintahan Modern Kekinian, CosmoGov: Jurnal Ilmu Pemerintahan Vol.3 No.2. 
p-ISSN : 2541-2345, e-ISSN : 2580-8842

Indonesia. ${ }^{10}$ Perbandingannya dengan penelitian ini yaitu lebih mengarah pada esensi bentuk pemerintahan.

Perbandingan kedua yaitu berawal dari implementasi konsep omnibus law di Indonesia. Pembahasan hierarkhi sesuai Undang-Undang Nomor 12 Tahun 2011 tentang Pembentukan Peraturan Perundang-undangan, belum memasukkan konsep omnibus law sebagai salah satu asas dalam sumber hukum maupun sebagai kerangka metodologis untuk melakukan revisi peraturan perundang-undangan. Secara teori perundang-undangan di Indonesia, kedudukan undang-undang dari konsep omnibus law belum diatur. Undang-undang hasil konsep omnibus law bisa mengarah sebagai payung karena mengatur secara menyeluruh dan kemudian mempunyai kekuatan terhadap aturan yang lain. Hasilnya adanya perubahan Perundang-undangan. Namun jika tidak dimungkinkan melakukan perubahan Undang-Undang Nomor 12 Tahun 2011 tentang Pembentukan Peraturan Perundang-undangan. Omnibus Law dalam bentuk UU bukan UU Pokok, tetapi UU yang setara dengan UU lain yang seluruh atau sebagian ketentuannya diubah atau dihapus dengan membuat norma baru Kesimpulan yang diberikan Agnes Fitryantica ini melihat dari sudut pandang efektivitas sehingga apabila berbicara efektivitas maka kemungkinan akan terjadi. ${ }^{11}$ Perbandingan yang digunaka belum menggunakan Undang-Undang Republik Indonesia Nomor 15 Tahun 2019 tentang Perubahan Atas Undang-Undang Nomor 12 Tahun 2011 Tentang Pembentukan Peraturan Perundang-Undangan namun dalam penelitian itu tidak membahas implikasi kepada bentuk pemerintahan ketika terjadi omnibus law. Hal ini berbeda dengan penelitian ini bahwa omnibus law menjadikan bentuk pemerintahan yang baru.

\section{B. Rumusan Masalah}

${ }^{10}$ Muhamad Azhar, Omnibus Law sebagai Solusi Hiperregulasi Menuju Sonkronisasi Peraturan Per-Undang-undangan di Indonesia Administrative Law \& Governance Journal, vol. 2, no. 1, pp. 170 - 178, Feb. 2019.

${ }^{11}$ Agnes Fitryantica, Harmonisasi Peraturan Perundang-Undangan Indonesia melalui Konsep Omnibus Law, Jurnal Gema Keadilan Volume 6, Edisi III, Oktober - November 2019. 
Berdasarkan uraian dalam latar belakang, maka rumusan masalah hanya mengambil satu yaitu bagaimana bentuk pemerintahan ketika omnibus law diterapkan?

\section{Metode Penelitian}

Penelitian ini tidak menggunakan penelitian normatif atau empiris dikarenakan apabila menggunakan metode tersebut akan terjadi pembatasan dalam menghasilkan kesimpulan. Walaupun ada pendapat bahwa metode saling melengkapi dan saling tergantung dalam memahami hukum namun penelitian ini cenderung menggunakan metode analitis hukum karena penelitian ini bersifat abstrak dan terlepas dari realitas sosial yang mendasarinya.

Mengandaikan apabila hasil penelitian menginginkan masyarakat yang lebih baik ketika bentuk pemerintahan atau menginginkan pemerintah yang mempertahankan Undang-Undang Dasar Negara Republik Indonesia Tahun 1945 maka metode analitis hukum adalah jalan keluarnya. Metode ini bertujuan menghasilkan kepastian hukum walaupun omnibus law belum dilakukan secara faktual. $^{12}$

${ }^{12}$ It should be clear that case law is not always offering a correct picture of the living law in a society. When, for instance, no case law can be found at all in some country, it may mean that the law has become obsolete, that the underlying societal problem has disappeared, but also that earlier problems as to the interpretation of the law have meanwhile been settled, so that cases are no longer brought to court, as everybody (or at least their counsellors) knows perfectly how to apply the law, Mark Van Hoecke, Methodology of Comparative Legal Research, Queen Mary, University of London, June 2015.

Pemahaman akan metode yang tidak objektif seringkali menjadikan peneliti tersesat. Faktanya, tiap metode apapun perlu diproduksi oleh individu tertentu yang terletak di ruang dan waktu. Disebut juga, metode apapun mengenali kontingen yang tak terelakkan karakter metode yang mereka adopsi, Pier Giuseppe Monateri, Methods of Comparative Law, Edward Elgar Publishing, Inc., Massachusetts, 2012, hlm. 67. 


\section{PEMBAHASAN}

\section{A. Bentuk Pemerintahan Murni Di Indonesia}

Dalam siklus yang dikehendaki oleh Plato, aristokrasi adalah terbaik karena ia adalah wujud dari para filsuf itu sendiri. Aristokrasi yang demikian terpecah menajdi dua bagian yaitu aristokrasi murni dan aristokrasi ${ }^{13}$ yang berisi kaum sofis. Mengacu

${ }^{13}$ Practically the same may be said about the timocratic and tyrannical regimes. The timocratic men are also "greedy for money, as men are in oligarchies," although "they will prize gold and silver without restraint . . . in secret" (548a). Moreover, their love for honor, glory, and victories seems to lead to another form of fierce competition, strife, and disunity. Again, Plato never says that timocracy is destroyed by "excessive" indulgence in honor because no "excess" is necessary. The timocratic man loves power, always tries to dominate others and to have his own way. Thus, both the timocratic and oligarchic men commit the same hubris against one another as Hesiod's silver and bronze races. The oligarchic and timocratic regimes are founded on the pursuit of the goods which are always in short supply, and the logic of timocratic domination as well as oligarchic exploitation leads to disunity, destructive competition, and natural selection one can neither prevent nor stop. Both regimes seem to have the same self-destructive tendency to disruption built in, both face the same dilemma of limited 
pemikiran Plato, maka demokrasi bukanlah hal terbaik tetapi ketika Presiden Joko Widodo mengemukakan omnibus law pada bentuk bentuk pemerintahan demokrasi maka dapat disebut sebagai bagian. Persamaan bagian bisa ditafsirkan sebagai wujud cara menyempurnakan demokrasi ${ }^{14}$ atau mempertahankan demokrasi.

Perubahan bentuk pemerintahan yang sering terjadi di Indonesia merupakan perubahan turunan artinya Indonesia tetap bersandar pada demokrasi namun turunannya berupa demokrasi terpimpin ataupun demokrasi dengan ideologi komunis.

\section{B. Bentuk Pemerintahan Mendatang}

Kajian negara hukum, negara adalah entitas yang selalu berkembang dan memiliki sifat yang monopoli dan mutlak. Ketika omnibus law diterapkan maka akan ada dua kemungkinan bentuk pemerintahan yang muncul yaitu demokrasi yang betulbetul murni artinya keinginan rakyat guna mempersingkat segala peraturan perundang-undangan akan terpenuhi.

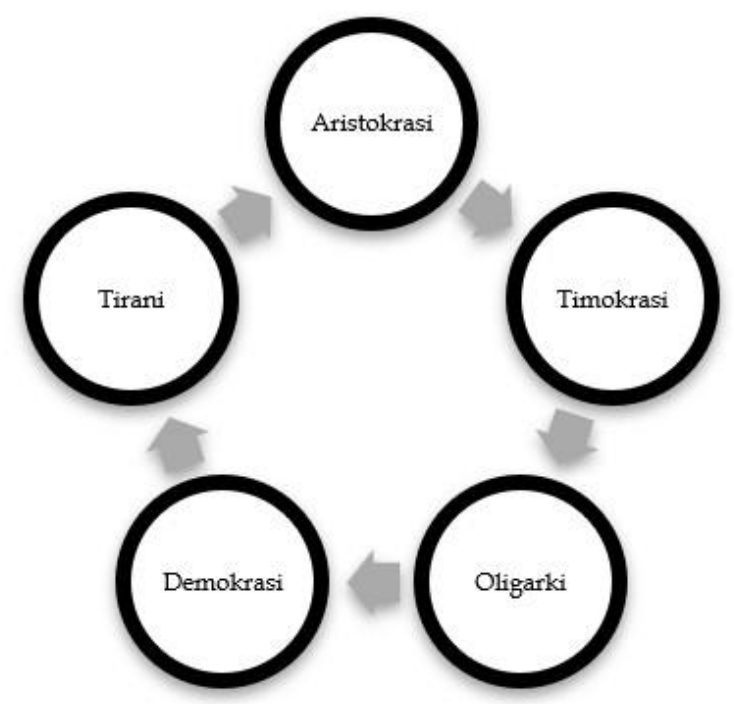

goods and unlir Democarcy?, Int ${ }^{14}$ Perhatikan ke] keraguan akan e:

:e For Plato's 7): $37-57$.

tto mengalami Objection To Democracy, Annales Universitäis Mariae Curie-Sklodowska Lublin - Polonia Vol. XXI, 1Sectio K, 2014.

Bandingkan dengan pemikiran al-Fārābī bahwa status negara adalah seimbang dan tidak satupun yang dapat melakukan klaim atas posisi mayoritas, sementara dalam hal lainnya jabatan politik dapat dibeli dengan harga, lebih lanjut dalam Muhammad Ali Khalidi, Al-Fārābī On The Democratic City, British Journal for the History of Philosophy 11(3) 2003: 379-394. 


\section{Gambar 1. Bentuk Pemerintahan Menurut Plato ${ }^{15}$}

Omnibus law apabila mengacu pada Undang-Undang Republik Indonesia Nomor 12 Tahun 2011 tentang Pembentukan Peraturan Perundang-Undangan dan terbaru Undang-Undang Republik Indonesia Nomor 15 Tahun 2019 tentang Perubahan Atas Undang-Undang Nomor 12 Tahun 2011 Tentang Pembentukan Peraturan Perundang-Undangan merupakan bagian dari undang-undang dan bisa menjadi peraturan pemerintah pengganti undang-undang.

Apabila mengacu pada bentuk pemerintahan demokrasi murni maka kemurnian itu adalah residu oligarki. Sebagaimana detail dalam Gambar 1., dijelaskan:

a. Aristokrasi dimana pemerintahan dipegang oleh kaum bijaksana.

b. Timokrasi dimana pemerintahan dipegang oleh orang-orang yang ingin mencapai kemasyhuran dan kehormatan.

c. Oligarki dimana pemerintahan dipegang oleh kaum hartawan.

d. Demokrasi dimana pemerintahan dipegang oleh rakyat jelata.

e. Tirani dimana pemerintahan oleh seorang yang bertindak sewenang-wenang.

Omnibus law juga bisa dikaitkan dengan tirani dalam demokrasi, artinya di dalam demokrasi terdapat tirani dimana presiden bertindak sebagai penguasa. ${ }^{16}$ Tirani ini dikaitkan dengan tujuan omnibus law yaitu memberi kemudahan bagi masyarakat maka tidak dapat disebut tirani murni melainkan bagian dari demokrasi.

${ }^{15}$ Plato, Republik, Jogjakarta, Bentang Budaya, 2002 dan Plato, The Great Dialogues Of Plato, Canada, Penguin Books Canada Limited, 1984.

${ }^{16}$ Bandingkan dengan pemahaman presiden sebagai kepala eksekutif dimana terdapat pembagian trias politika. 


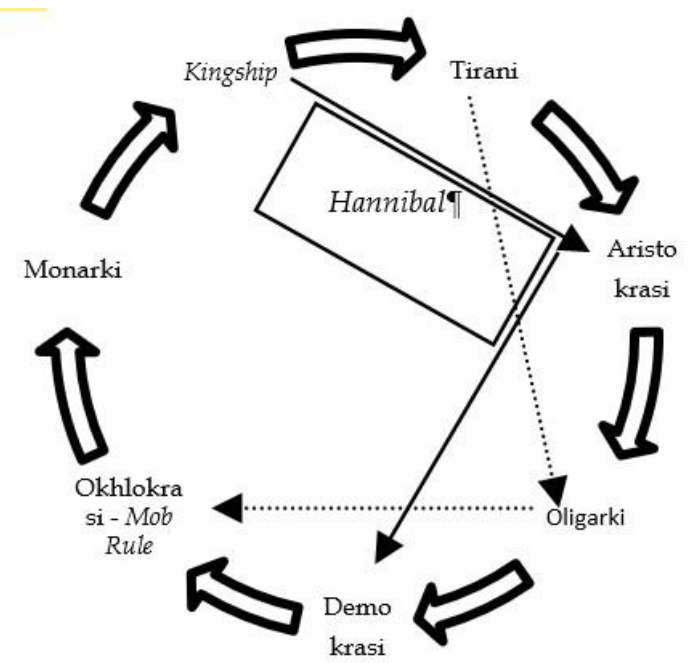

Gambar 2. Bentuk Pemerintahan Menurut Polybius ${ }^{17}$

Pendapat berbeda tercermin dalam pemikiran Polybius (Gambar 2.) bahwa kingship yang diartikan sebagai pemimpin bersumber pada ajaran agama bisa berubah menjadi aristokrasi ketika ajaran agama disalahgunakan, bentuk perubahan disebut sebagai hannibal. Siklus yang menjadi poin utama adalah demokrasi yang selalu mendapat bentuk pada bagian akhir. Demokrasi merupakan awal sebelum terjadi okhlokrasi dan akhirnya menjadi monarki. Monarki disini bukanlah kerajaan namun pemimpin yang bersifat semena-mena. Pertautan antara Plato dan Polybius terletak mendeskripsikan demorkasi sebagai bagian akhir dari siklus bentuk pemerintahan yaitu bentuk pemerintahan yang terjadi akibat adanya kekuasaan oleh satu orang saja.

\section{PENUTUP}

Bentuk pemerintahan perspektif omnibus law adalah demokrasi gabungan Plato dan Polybius karena tujuan akhir adalah kesejahteraan masyarakat. Gabungan ini menjadikan demokrasi di Indonesia memiliki arti bentuk pemerintahan dalam membatasi kekuasaan negara. Presiden bertindak sesuai dengan Undang-Undang Dasar Negara Republik Indonesia Tahun 1945. Sebagai saran yang dikemukakan bahwa penerapan omnibus law harus segera dilakukan terhadap satu tema undangundang saja misalnya agraria maka omnibus law-nya harus agraria ataupun hukum teknologi. Penerapan omnibus law tetap harus melalui pengawasan Dewan Perwakilan

\footnotetext{
${ }^{17}$ Polybius, The Rise Of The Roman Empire, England, Penguin Books.
} 
p-ISSN : 2541-2345, e-ISSN : 2580-8842

Rakyat agar tercipta check and balances serta partisipasi masyarakat sesuai UndangUndang Republik Indonesia Nomor 15 Tahun 2019 tentang Perubahan Atas UndangUndang Nomor 12 Tahun 2011 Tentang Pembentukan Peraturan PerundangUndangan.

\section{Buku}

\section{Daftar Pustaka}

Pier Giuseppe Monateri, Methods of Comparative Law, Edward Elgar Publishing, Inc., Massachusetts, 2012.

Plato, The Great Dialogues Of Plato, Canada, Penguin Books Canada Limited, 1984. , Republik, Jogjakarta, Bentang Budaya, 2002.

Polybius, The Rise Of The Roman Empire, England, Penguin Books.

Tom Todd, The Research Department of the Minnesota House of Representatives, Minnesota, 2018.

Jurnal

Agnes Fitryantica, Harmonisasi Peraturan Perundang-Undangan Indonesia Melalui Konsep Omnibus Law, Jurnal Gema Keadilan Volume 6, Edisi III, Oktober November 2019. DOI: 10.14710/gk.6.3.300-316

Arif Hidayat dan Zaenal Arifin, Politik Hukum Legislasi Sebagai Socio-Equilibrium Di Indonesia, Jurnal Ius Constituendum |Volume 4 Nomor 2 Oktober 2019 Magister Hukum Program Pascasarjana Universitas Semarang. DOI : 10.26623/jic.v4i2.1654

Carol Li, A Repeated Call For Omnibus Federal Cybersecurity Law, Notre Dame Law Review, Vol. 94:5.

Denis Kirchhoff and Leonard J.S. Tsuji, Reading between the lines of the 'Responsible Resource Development' rhetoric: the use of omnibus bills to 'streamline' Canadian environmental legislation, Impact Assessment and Project Appraisal, 2014 Vol. 32, No. 2; Louis Massicotte, Omnibus Bills in Theory and Practice, Canadian Parliamentary Review, 2013.

Firman Freaddy Busroh, Konseptualisasi Omnibus Law Dalam Menyelesaikan Permasalahan Regulasi Pertanahan, ARENA HUKUM Universitas Brawijaya, Volume 10, Nomor 2, Agustus 2017.

DOI https://doi.org/10.21776/ub.arenahukum.2017.01002.4

Glen S. Krutz, Tactical Manuevering on Omnibus Bills in Congress, American Journal of Political Science, Vol 45, No 1 (January 2001).

Kurt Taylor Gaubatz, Kant, Democracy And History, Journal of Democracy Volume 7 Number 4 October 1996.

McCabe, Margaret Sova (2018) "Cooperation or Compromise? Understanding the Farm Billas Omnibus Legislation," Journal of Food Law \& Policy: Vol. 14 : No. 1 , Article 5.

Muhamad Azhar, Omnibus Law sebagai Solusi Hiperregulasi Menuju Sonkronisasi Peraturan Per-Undang-undangan di Indonesia Administrative Law \& Governance Journal, Vol. 2, No. 1, Feb. 2019. DOI: 10.14710/alj.v2i1.170 - 178 
Muliadi Anangkota, Klasifikasi Sistem Pemerintahan Perspektif Pemerintahan Modern Kekinian, CosmoGov: Jurnal Ilmu Pemerintahan Vol. 3 No. 2. DOI $\underline{10.24198 / \operatorname{cosmogov} . v 3 i 2.14725}$

Muten Nuna dan Roy Marthen Moonti, Kebebasan Hak Sosial Politik Dan Pasrtisipasi Warga Negara Dalam Sistem Demokrasi Di Indonesia, Jurnal Ius Constituendum Volume 4 Nomor 2 Oktober 2019, Program Pascasarjana Universitas Semarang. DOI : 10.26623/jic.v4i2.1652

Robert L. Nightingale, How To Trim a Christmas Tree: Beyond Severability and Inseverability for Omnibus Statutes, 125 Yale L.J. (2016).

Tara Leigh Grove, Symposium Foreword: Some Puzzles Of State Standing, Notre Dame Law Review, Vol. 94:5.

Waldemar Hanasz, Poetic Justice For Plato's Democarcy?, Interpretation: A Journal Risalah of Political Philosophy, vol. 25, No. 1 (Fall 1997).

Louis Massicotte, Omnibus Bills in Theory and Practice, Canadian Parliamentary Review/Spring 2013.

Pidato Sidang Paripurna Majelis Permusyawaratan Rakyat Republik Indonesia Dalam Rangka Pelantikan Presiden Dan Wakil Presiden Terpilih 2019-2024. 